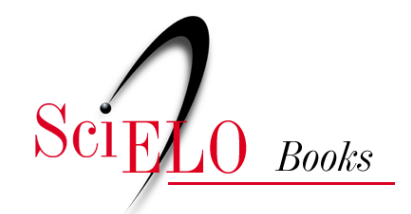

\title{
Teatro contemporâneo o sentido em debate
}

\author{
José da Costa
}

COSTA, J. Teatro contemporâneo: o sentido em debate. In: FLORENTINO, A., and TELLES, N., eds. Cartografias do ensino do teatro [online]. Uberlândia: EDUFU, 2008, pp. 117-131. ISBN 97885-7078-518-3. https://doi.org/10.7476/9788570785183.0013.

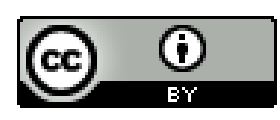

All the contents of this work, except where otherwise noted, is licensed under a Creative Commons Attribution 4.0 International license.

Todo o conteúdo deste trabalho, exceto quando houver ressalva, é publicado sob a licença Creative Commons Atribição $\underline{4.0}$.

Todo el contenido de esta obra, excepto donde se indique lo contrario, está bajo licencia de la licencia $\underline{\text { Creative Commons }}$ Reconocimento 4.0. 


\section{TEATRO CONTEMPORÂNEO: O SENTIDO EM DEBATE}

José da Costa

Segundo Nelson de Sá, Nova velha estória, espetáculo que Antunes Filho realizou a partir do conto de Chapeuzinho vermelho dos irmãos Grimm, era uma espécie de panfleto contra o teatro visual: "O diretor, com 40 anos de teatro, chutou glórias passadas e saiu a campo contra o teatro ininteligível, de imagens e gelo seco”. Com essas palavras, o crítico paulista se referia aos procedimentos cênicos utilizados por Gerald Thomas. Nelson de Sá justifica o caráter de obviedade que enxerga nos signos e na dramaturgia de Nova velha estória como uma maneira pela qual Antunes Filho estaria contrapondo-se à rarefação do significado em certo teatro brasileiro contemporâneo e como uma reação ao chamado teatro visual. A referência a Gerald Thomas, no comentário à peça de Antunes, explicita-se sem ambigüidade:

Nova velha história é, por assim dizer, o fundo do poço. Depois de cinco anos de Gerald Thomas, era preciso uma "terra arrasada" para mudar. O próprio Thomas tentou isso com Morte, espetáculo contido, apesar do título. A peça de Antunes Filho é um novo passo nessa direção. Um espetáculo mais para destruir do que para apontar alternativas ${ }^{1}$.

Mas não é só Nelson de Sá que se inquieta com o crescimento do suposto teatro visual no Brasil durante os anos 80 e 90 . Em edição da Revista da Universidade de São Paulo - USP -, dedicada ao teatro brasileiro contemporâneo, a pesquisadora Tânia Brandão discute o panorama teatral do Rio de Janeiro naquele momento ${ }^{2}$. Preocupavam, então, à ensaísta a automatização dos intérpretes em decorrência da primazia dada à "materialidade plástica que os envolve" no teatro de Gerald Thomas, mas também no de Bia Lessa, em cujo trabalho "a direção de ator e os problemas de interpretação não são valorizados”. Essa espécie de redução do papel criativo desempenhado pelo ator atingia também, conforme as avaliações de Tânia Brandão, as produções lideradas por Moacyr Góes e por Márcio Vianna à época em que o ensaio foi escrito. Nas peças desses dois últimos diretores, a exacerbação da intensidade corporal, a qual os intérpretes eram levados, acarretaria o prejuízo da capacidade de modulação da emoção e da enunciação do texto na visão de Tânia.

\footnotetext{
${ }^{1}$ SÁ, Nelson de. Divers/Idade: um guia para o teatro dos anos 90. São Paulo: Hucitec, 1997. p. 49.

2 BRANDÃO, Tânia. Visionários ou alienados. Revista da USP, São Paulo, n. 14, p. 28-33, jun./ ago. 1992.
} 
No trabalho dos quatro diretores tomados como representantes das tendências dominantes no teatro carioca no final dos anos 80 e início dos 90 , a ensaísta verifica outro traço comum. Trata-se de uma segunda redução, aquela imposta à função do texto verbal, levando a uma espécie de "morte da palavra", que teria a ver com razões diversas interligadas entre si. A rejeição por vários daqueles diretores de encenarem textos disponibilizados pelo repertório da literatura dramática ocidental seria uma das causas do sacrifício da palavra diagnosticado pela pesquisadora carioca. A única exceção seria Moacyr Góes, que lançou mão de obras de Brecht, Büchner, Marlowe, Guelderode, Sakespeare e Sófocles em sua trajetória de encenador. Entretanto, na visão de Tânia Brandão, a ênfase dada à corporeidade (em uma orientação mecânica ou automatizada) reduzia a importância do texto nos empreendimentos teatrais realizados por Moacyr.

Entre as razões da dupla redução da palavra e do ator, a ensaísta menciona a tendência a se priorizarem narrativas de ficção livremente teatralizadas a partir das exigências dos projetos cênico-visuais dos diretores (Thomas em relação a obras de Kafka, Bia Lessa em relação à de Virgínia Wolf etc.); bem como uma tendência aparentada à primeira, qual seja, a de os próprios encenadores escreverem textos "em geral, bem pouco densos, desprovidos de relevância enquanto dramaturgia e até de importância secundária na dinâmica da montagem”’. Para Tânia Brandão:

\begin{abstract}
Não há dúvida de que as tendências teatrais cariocas mais recentes e de maior repercussão acontecem tendo como pano de fundo o processo de diluição da linguagem teatral moderna, cuja institucionalização não ocorreu plenamente. Por isso, parece preocupante que essas novas tendências reúnam produtores que, dedicados à livre criação e à expressão pessoal de seu ideário, não tenham um cálculo nítido de diálogo ou atrito com os temas da modernidade histórica. Não há como não sentir um sabor amargo quando se constata que certos temas, onipresentes e cruciais para o teatro do século XX, não são trabalhados ou são descartados com razoável facilidade. Pode ser que aí esteja o teatro do futuro, o rascunho da cena do século XXI - a distância frente ao problema do sentido, o abandono do conceito tradicional de ação dramática, a ênfase na plasticidade e na construção visual, o desprezo ou a indiferença diante da hipótese da palavra, a automatização do ator seriam indícios de uma cena-de-um-outro-tempo-que-virát.
\end{abstract}

Tânia Brandão tem desenvolvido em vários trabalhos a visão de que o viés dominante no teatro brasileiro atual, centrado em certo tipo de estrelismo dos diretores (no teatro mais experimental) e dos atores (no teatro mais comercial), implica uma espécie de desvio ou degeneração do movimento modernizante da cena nos anos 40 e 50. Movimento esse que não teria, como demonstra a estudiosa, apenas focalizado a construção de uma poética da encenação, mas teria também realizado esforços de transformação do mercado profissional e da inserção institucional do teatro, ainda que esses esforços não tivessem atingido, conforme a avaliação de Tânia Brandão, suficiente consistência ou continuidade ${ }^{5}$.

\footnotetext{
BRANDÃO, 1992, p. 32.

BRANDÃO, 1992, p. 33.

5 Um exemplo de trabalho em que Tânia Brandão aborda essas questões é o brilhante ensaio
} 
O movimento modernizante do teatro no Brasil se iniciou no Rio de Janeiro pelos amadores (Teatro Brasileiro do Estudante e Os Comediantes, fundamentalmente) e, profissionalmente, foi empreendido pelo TBC e pelas companhias dele procedentes ou a ele aparentadas em termos de projeto artístico-cultural, como, por exemplo, o Teatro Popular de Arte de Sandro Polonio e Maria Della Costa, surgido, como o TBC, no ano de 1948. É, aliás, ao Teatro Popular de Arte (que surge no Rio de Janeiro e só depois se transfere para São Paulo) que Tânia dá a primazia em termos de profissionalização de uma prática teatral moderna no Brasil ${ }^{6}$.

$\mathrm{O}$ afastamento com relação ao moderno detectado por Tânia no palco contemporâneo começaria, segundo sua avaliação, na fase nacional-popular do Teatro de Arena de Boal, Vianinha e Guarnieri, no final dos anos 50; atingiria, ainda em São Paulo, o Teatro Oficina de José Celso Martinez Correia, a partir de seu momento tropicalista com a encenação de $O$ rei da vela, de Oswald de Andrade, em 67; instalando-se também, no Rio de Janeiro, em uma companhia como o Teatro Ipanema de Ivan de Albuquerque e de Rubens Correia no início dos anos $70^{7}$. O resultado do desvio de rota ou desagregação do teatro moderno seria um teatro que se aproxima da prática pré-moderna - segundo os termos da própria autora ${ }^{8}$-, experiência de tipo voluntarista, dos grandes atores dos anos 30 e 40, a exemplo de um Procópio Ferreira e de um Jaime Costa ${ }^{9}$ e tradição iniciada no contexto romântico oitocentista de João Caetano ${ }^{10}$. $\mathrm{Na}$ densa e complexa discussão da noção de moderno, em sua tese de doutoramento, a autora tem o cuidado de evitar dualismos como, por exemplo, o do binômio avançado-atrasado como correspondente da dicotomia moderno versus não-moderno ${ }^{11}$. Esse cuidado aponta para a percepção de que esses dualismos acabam por desqualificar um dos termos da oposição, como desqualificam também todas as alternativas que escapam à versão priorizada hierarquicamente, podendo gerar, como conseqüência, raciocínios históricos unilaterais ou unívocos.

Mas de modo crucial, o que parece à pesquisadora estar na base do subjetivismo voluntarista que vê nos trabalhos dos diretores, no final dos anos 80 e início dos 90 no Rio de Janeiro, é o desprezo "frente ao problema do sentido" e o "abandono do conceito tradicional de ação dramática”. São esses os fatores que reduziriam a um papel secundário tanto as palavras, quanto os intérpretes no teatro carioca do período comentado no texto da Revista da USP.

Nesse ensaio, Tânia Brandão explicita a posição de que a co-habitação de referências a contextos histórico-culturais muito díspares em uma mesma obra seria, em sua

Teatro brasileiro do século $X X-$ As oscilações vertiginosas. BRANDÃO, Tânia. $\mathrm{O}$ teatro brasileiro do século 20. Revista do IPHAN, Brasília, DF, n. 29, p. 300-335, 2001b. Mas também na tese de doutoramento da pesquisadora, Peripécias modernas: companbia Maria Della Costa (19481974), aparece o tema da extinção da experiência do teatro moderno no Brasil a partir da década de 60 e principalmente de 70. BRANDÂO, Tânia. Peripécias modernas: Companhia Maria Della Costa (1948-1974). 1998. p. 323, 332. Tese (Doutorado) - Instituto de Filosofia e Ciência Sociais, Universidade Federal do Rio de Janeiro, Rio de Janeiro, 1998. Não publicada. O interesse da historiadora pelo percurso de um certo teatro moderno profissional aparece ainda no livro em que estuda a trajetória da companhia carioca Teatro dos Sete. BRANDÃO, Tânia. A máquina de repetir e a fábrica de estrelas: Teatro dos Sete. Rio de Janeiro: 7 Letras, 2002. 330 p.

6 BRANDÃO, 2001b, p. 320

7 BRANDÃO, 2001b, p. 325-326, 329.

8 BRANDÃO, 1992, p. 33.

9 BRANDÃO, 2001b, p. 315, 324.

${ }^{10}$ BRANDÃO, 2001b, p. 303-305, 309.

${ }^{11}$ BRANDÃO, 1998, p. 1-69. 
opinião, um dos exemplos da atitude voluntarista dos diretores. Trata-se de um trecho em que a ensaísta se refere a Gerald Thomas como sendo, dentre os diretores citados (Moacyr Góes, Bia Lessa e Márcio Vianna, além do próprio Thomas), aquele:

[...] cujos trabalhos estão mais estreitamente ligados à própria personalidade e aos maneirismos do criador, inclusive devido às citações gratuitas, episódicas ou anedóticas de outras obras de arte (o caso mais grave, aqui [no Rio de Janeiro] foi a montagem da ópera $O$ navio fantasma, de Wagner, em que o diretor se deu ao luxo de se referir à Documenta de Kassel e a obras de artes plásticas do século XX ${ }^{12}$.

Em suma, os procedimentos de aglutinação de referências díspares, as técnicas de colagem e de montagem, associando aspectos relativos a contextos históricos e culturais heterogêneos, foram vistos pela pesquisadora em certo momento como sintoma de uma espécie de subjetivismo gratuito e, por isso, reprovável.

Sábato Magaldi, em seu ensaio de abertura da mesma publicação ${ }^{13}$, compartilha, de certo modo, o tipo de visão expressa por Tânia Brandão sobre o teatro do início dos anos 90, afirmando ser recomendável:

Que os encenadores-criadores admitam um pouco mais de modéstia, reflitam que não são deuses todo-poderosos e acolham a colaboração de dramaturgos e intérpretes, já que o bom senso diz que não se faz bom teatro sem boa literatura ${ }^{14}$.

Já Alberto Guzik ${ }^{15}$ não reproduz esse apelo ao "bom senso", naturalizado nas palavras de Magaldi, que opta por recorrer às noções de "bom teatro" e de "boa literatura", como se elas fossem auto-evidentes e não necessitassem maiores especificações de critérios ou de perspectivas segundo as quais se possa aludir às mesmas. Apesar de não recorrer à expressão tão singela quanto "boa literatura", Guzik também lida com a dicotomia teatro da palavra versus teatro da imagem, a que se refere como "dramaturgia do espaço", exercida, segundo ele, por encenadores como Bia Lessa, Ulysses Cruz e Gerald Thomas.

Estamos em um determinado campo de apreciação do teatro contemporâneo que, apesar de diferenças em vários níveis, considerando os distintos perfis intelectuais, profissionais e geracionais dos críticos mencionados, compartilha certa perspectiva comum no que diz respeito ao modo de entender determinados aspectos do teatro atual. De fato é, por exemplo, bastante habitual, em vários setores da crítica jornalística e acadêmica, uma visão razoavelmente pessimista (expressa, muitas vezes, também em depoimentos de artistas) em relação à tendência do teatro contemporâneo de priorizar adaptações de textos originalmente não escritos para a cena; a encenação integral de narrativas de ficção razoavelmente longas; e, ainda, a ênfase dada nas composições dramatúrgicas empreendidas pelos próprios encenadores (e/ou por dramaturgos ou dramaturgistas integrados às companhias), às técnicas de colagem, de montagem literária, de bricolagem e de livre manipulação de referências artísticas

\footnotetext{
12 BRANDÃO, 1992, p. 32.

${ }_{13}$ MAGALDI, Onde está o teatro. Revista da USP, São Paulo, n. 14, p. 6-9, jun./ago. 1992.

${ }^{14}$ MAGALDI, 1992, p. 8.

${ }^{15}$ GUZIK, Alberto. Um exercício de memória: dramaturgia brasileira anos 80. Revista da USP, São Paulo, n. 14, p. 10-15, jun./ago. 1992.
} 
e culturais. Esses procedimentos de criação escapam ao que, do ponto de vista do drama tradicional e do play-writing mais atual, é considerado o domínio da chamada carpintaria dramatúrgica, da eficiência no ofício especializado da composição do texto dramático, entendido dentro das pautas particulares de um gênero definido ou de certa expectativa de comunicabilidade com o público médio.

Entre as ressalvas de Bárbara Heliodora em relação ao espetáculo $A$ paixão segundo G.H., com adaptação teatral do romance de Clarice Lispector assinada por Fauzi Arap e direção de Enrique Diaz, o aspecto dramatúrgico foi especialmente destacado e serviu a uma avaliação mais geral de certa tendência do teatro brasileiro atual.

Trata-se, portanto, de mais um exemplo da síndrome da literatura que vem atacando o teatro nacional nesses últimos tempos. Se fazer teatro não é fácil, não chega a ser muito compreensível esse insistente acréscimo nos obstáculos a serem superados até a hora do espetáculo, pelo uso de textos que não foram criados para o palco ${ }^{16}$.

$$
* * *
$$

Patrice Pavis, não partilhando da sensação de incompreensibilidade a que alude Bárbara Heliodora, apresenta uma outra visão do mesmo fenômeno no contexto francês:

Ninguém (exceto os teóricos do drama) acredita mais na especificidade do texto dramático, na existência de regras e de leis do diálogo, do personagem, da estrutura dramática, etc. Por prova, esta pesquisa de textos não escritos inicialmente para a cena e que permitiram as experiências do teatro-relato. [...] Trata-se de tomar o texto romanesco não como substrato para uma fábula e personagens, mas de fazer uma leitura cênica daquele texto mais ou menos dramatizada pelas improvisações de seus diversos leitores ${ }^{17}$.

Jacó Guinsburg, em texto que focalizava um outro aspecto, incluído na mesma publicação da USP a que venho recorrendo aqui, questionava a recepção crítica de certo teatro contemporâneo:

O fato de o teatro dos anos 80 distinguir-se por ser em grande parte criação de diretores, e muito menor escala de dramaturgos, suscitou na literatura especializada uma sucessão de especulações sobre a impotência teatral da escritura dramatúrgica como sinal de fenecimento da arte dramática. Nem o surgimento de autores como Heiner Müller, Botho Strauss e outros é considerado como uma demonstração de poder criativo de textualização, sendo apontado como confirmação do processo de decadência, pelas características de suas peças. As colagens, as citações, as montagens de fragmentos, as transposições do épico para o dramático, os enredos soltos, as estruturas abertas e a

${ }_{16}$ HELIODORA, Bárbara. Cuidados e carinhos com Clarice. O Globo, Rio de Janeiro, 4 dez. 2002. Segundo Caderno, p. 4.

17 PAVIS, Patrice. Le théâtre au croisement des cultures. Paris: Librairie José Corti, 1990. p. 74. Tradução nossa. 
própria potencialização dos recursos e das intervenções cênico-diretoriais tornam-se outros tantos argumentos em favor da desvitalização da força do teatro, de seus componentes essenciais e constitutivos, e não são tidos como elementos de uma linguagem que faz da montagem de teatro um teatro de montagem ${ }^{18}$.

No mesmo número da Revista da USP em que aparecem os ensaios de Tânia Brandão, Sábato Magaldi, Alberto Guzik e Jacó Guinsburg, dentre outros autores e autoras, chama a atenção a posição expressa por Sílvia Fernandes:

Para desobstruir o palco dos rótulos ou, pelo menos, observá-lo sob nova luz, é preciso enxergar no trabalho autoral de (Gerald) Thomas uma das matrizes de análise da encenação nos anos 80. [...] As peças musicais de Hamilton Vaz Pereira, as experiências plásticas e espaciais de Bia Lessa, o Corpo de baile de Ulysses Cruz ou o $A$ bao a qu de Enrique Diaz afirmam-se, tanto quanto a ópera seca de Thomas, como concretizações de um discurso da encenação ${ }^{19}$.

Sílvia Fernandes se aproxima de Guzik, uma vez que a idéia de um "discurso da encenação" se associa a de uma "dramaturgia do espaço", a que alude o crítico paulista. Em seu livro sobre o teatro de Thomas, Sílvia dedica um dos capítulos ao estudo da construção cênico-dramatúrgica a partir da análise do espaço, do tipo de sintaxe livre ou aberta que ali é proposta por meio de repetições, de citações e de variações de quadros cênicos e cenográficos. Sílvia Fernandes também se une a Tânia Brandão, uma vez que, como Tânia, ela enxerga, nos anos 80, uma espécie de retorno a uma autoria individualizada e centralizada nas mãos do encenador. Para Sílvia, essa tendência marca uma diferenciação em relação tanto às experiências de criação coletiva dos anos 70, quanto à concepção da encenação teatral como criação espetacular que se dá a partir de um texto dramático prévio ${ }^{20}$.

Apesar da aproximação sob certos aspectos, Sílvia Fernandes apresenta uma perspectiva claramente diferenciada em relação àqueles que fazem do trabalho cênico de Thomas o paradigma de um teatro semanticamente estéril:

18 GUINSBURG, Jacó. O lugar do teatro no contexto da comunicação de massa. Revista da USP, São Paulo, n. 14, p. 92-96, jun./ago. 1992b. A posição de Jacó Guinsburg mais aberta a certas práticas criativas contemporâneas aparece igualmente em texto da Revista Sala Preta (GUINSBURG, Jacó. Texto ou pretexto. Sala Preta: Revista de Artes Cênicas, São Paulo, ano 1 , n. 1, p. 87-88, 2001), como pode também ser pressuposta a partir de pelo menos alguns dos ensaios escritos a quatro mãos reunidos no livro Diálogos sobre teatro. GUINSBURG, Jacó. Diálogos sobre teatro. Organização de Armando Sérgio da Silva. São Paulo: Edusp, 1992a. 262 p. Lembre-se ainda que o autor é um dos organizadores do livro coletivo Um encenador de si mesmo: Gerald Thomas. FERNANDES, Sílvia; GUINSBURG, Jacó (Org.). Um encenador de si mesmo: Gerald Thomas. São Paulo: Perspectiva, 1996. 295 p.

${ }_{19}$ FERNANDES, Sílvia. O espectador emancipado. Revista da USP, São Paulo, n. 14, p. 70-71, jun./ago. 1992.

${ }_{20}$ Sílvia Fernandes - que se dedicara aos grupos de teatro dos anos 70 em estudo realizado antes da pesquisa sobre a obra de Thomas, ainda que publicado posteriormente (FERNANDES, Sílvia. Grupos teatrais: anos 70. São Paulo: UNICAMP, 2000a. 268 p.) - enxerga hoje, no Teatro da Vertigem de Antônio Araújo, o exemplo de uma mentalidade (a da prática colaborativa de criação cênica e dramatúrgica) que não se coaduna nem com o espírito da criação coletiva da década de 70 e nem com o domínio do encenador verificado nos anos 80 (FERNANDES em NESTROVSKI, Arthur (Org.). Trilogia bíblica: teatro da vertigem. São Paulo: Publifolha, 2002. p. 35-40). Para a pesquisadora, o Teatro da Vertigem aponta um outro modo de criação participativa, envolvendo simultaneamente encenador, atores e dramaturgo. 
Muitas críticas começaram a alvejar o teatro de Thomas. Estetização, hermetismo, auto-referência, simulacro, eram alguns dos conceitos que rotulavam o palco do encenador. Subjacente a elas, o que estava em jogo era um determinado conceito de teatro, construído pacientemente desde Aristóteles. Teatro de verdade tinha de ter conflito, texto dialogado, ator identificado (ou, quando muito, distanciado) e se possível, nó dramático. E no caso de Thomas, o jogo da teatralidade se desenrolava através das imagens em cena ${ }^{21}$.

A pesquisadora se refere aqui às críticas que Thomas começou a receber no Brasil a partir da exibição dos primeiros espetáculos realizados como composições inteiramente escritas pelo próprio Thomas, como Electra com Creta (Rio de Janeiro, 1985) e Carmen com filtro (São Paulo, 1986) e não como encenações de textos de outros autores, a exemplo de Quatro vezes Beckett (Rio de Janeiro, 1985), com textos curtos de Samuel Beckett, e de Quartet, de Heiner Müller (Rio de Janeiro, 1986).

Sílvia Fernandes havia antecipado, em seu ensaio da Revista da USP, aspectos que viriam a ter um desdobramento mais extenso na tese sobre o teatro de Gerald Thomas, que veio a defender e publicar alguns anos depois. Estudo em que dedica um dos capítulos à discussão da construção da personagem pelo encenador-dramaturgo Gerald Thomas e pela atriz Bete Coelho no espetáculo Carmen com filtro. Nesse capítulo, a pesquisadora chama a atenção para a composição por procedimentos de acumulação de referências literárias e histórico-culturais muito variadas e mesmo díspares sobre o suporte da figura de Carmen, destacando ainda a importância da colaboração criativa de Bete Coelho no espetáculo.

No ensaio da Revista da USP, a ensaísta confronta o fechamento do palco por uma cortina de filó (colocada no proscênio em algumas das encenações de Gerald Thomas) com a teorização da quarta parede na perspectiva naturalista de André Antoine. A pesquisadora, ao contrário de Tânia Brandão, apreende, assim, um diálogo (com diferenciação) do trabalho de Thomas com certas experiências fundantes do teatro moderno do início do século passado.

O fechamento do palco contemporâneo não parece obedecer a essa necessidade (refere-se à demanda de ilusão teatral, que marcara a produção de André Antoine no início do século XX). Em primeiro lugar porque aquilo que vemos em cena (no caso do teatro de Thomas) é ficção elevada à última potência, ou melhor, é desestabilização dos mecanismos de preservação da ficção. Em segundo, porque a representação não pretende entregar ao público um sentido, uma visão de realidade, uma mensagem ou qualquer outro elemento exterior a ela ${ }^{22}$.

Sílvia Fernandes enxerga no teatro de Gerald Thomas o "esboço de uma nova concepção de representação”, que não opera a partir da unificação dos elementos de cena, com a redução de sua possível heterogeneidade, visando à construção unitária de um sentido comum. Como lembra a pesquisadora, esse modo de operar - com aplainamento do heterogêneo - está na base das práticas do modernismo teatral

${ }^{21}$ FERNANDES, Sílvia. Memória e invenção: Gerald Thomas em cena. São Paulo: Perspectiva, 1996. p. X.

${ }^{22}$ FERNANDES, 1992, p. 72. 
desde suas primeiras teorizações em Wagner, em Craig ou em Adolph Appia.

Segundo Patrice Pavis, o sentido no teatro pós-moderno é marcado pela mobilidade ou provisoriedade num grau que não se via no teatro moderno da primeira metade do século $\mathrm{XX}^{23}$. Nesse último, as operações de harmonização dos elementos sígnicos e semânticos tenderiam, conforme o pensamento do teórico francês, a produzir certas sínteses significacionais após todas as dispersões (temporais, espaciais etc.) que tenham por ventura sido admitidas e todas as contradições dialéticas que tenham sido acionadas ao longo da peça, ou seja, tenderiam a constituir uma univocidade e uma estabilidade controladora das possíveis derivas do sentido. De fato, são as operações harmonizadoras e estabilizadoras do sentido que parecem ser colocadas fortemente em questão por certo teatro dos dias atuais.

No Brasil, não é apenas a voz de jornalistas ou de estudiosos que se levanta em defesa de um princípio de causalidade e de certo tipo de narratividade linear ou de base referencial mais estável. Muitos criadores, em depoimentos públicos e em textos de reflexão, apegam-se a essa perspectiva. Adere-se a ela, várias vezes, como um modo de recuperar platéias perdidas para outras formas de lazer e distração. $\mathrm{O}$ dramaturgo Luiz Alberto Abreu ${ }^{24}$, por exemplo, defende, em dois artigos publicados recentemente em revistas acadêmicas de teatro, tanto a retomada de eixos narrativos razoavelmente unificados e harmônicos - mesmo mencionando, contraditoriamente, exemplos de autores que não trabalham nessa perspectiva como Heiner Müller e Bernard-Marie Koltés ${ }^{25}$-, quanto de personagens estáveis e contínuos, capazes de ter uma consciência de si e do mundo ${ }^{26}$.

Para Abreu, a revalorização da dimensão narrativa seria fundamental para a reaproximação do teatro em relação ao público, que ter-se-ia distanciado, em decorrência da perda da capacidade dos criadores de falarem "a mesma língua" que os espectadores, de veicularem "imagens extraídas de um imaginário comum”27. A recuperação dessa capacidade, fazendo o teatro voltar a tocar no que o dramaturgo chama de "imaginário coletivo" e levando à superação dos "guetos com suas diminutas platéias"28 poderá contribuir, na opinião do dramaturgo, para a criação ou reconstituição de laços mais gerais entre as pessoas, laços de tipo comunitário ou nacional.

Penso que a defesa do aspecto narrativo, no texto da Revista O Percevejo, faz Luiz Alberto Abreu confundir os traços formais de um teatro narrativizado (a presença de coros, narradores etc.) com algo que é distinto disso que é o eixo narrativo-diegético (fabular) do texto teatral, tenha esse texto um formato dramático mais fechado ou rompa ele o caráter absoluto da ação, por meio da utilização de traços épico-líricos. De fato, o que o dramaturgo, nos ensaios mencionados, está defendendo (talvez sem maior

\footnotetext{
${ }^{23}$ PAVIS, 1990, p. 65-87, 89-108; PAVIS, Patrice. Vers une théorie de la pratique théâtrale: voix et images de la scène. Septentrion: Presses universitaires de Septentrion, 2000. p. 193-206.

${ }^{24}$ Luiz Alberto Abreu é autor de peças como Foi bom, meu bem?, Bella Ciao, Lima Barreto ao terceiro dia e guerra santa dentre outras, tendo diversas vezes trabalhado como dramaturgo no interior de projetos de certos grupos de teatro como, por exemplo, o Grupo Galpão e Teatro da Vertigem.

${ }_{25}$ ABREU, Luiz Alberto. A restauração da narrativa. O Percevejo: Revista de Teatro, Crítica e Estética, Rio de Janeiro, ano 8, n. 9, p. 115-125, 2000.

26 ABREU, Luís Alberto. A personagem contemporânea: uma hipótese. Sala Preta: Revista de Artes Cênicas, São Paulo, ano 1, n. 1, p. 61-68, 2001.

${ }^{27}$ ABREU, 2000, p. 121.

${ }^{28}$ ABREU, 2000, p. 121.
} 
consciência desse fato) parece ser a retomada de determinados valores de caráter bastante tradicional na história da arte e da literatura ocidentais, valores que tiveram uma configuração mais objetiva nos séculos XVIII e XIX e que dizem respeito a funções pedagógicas da ficção (narrativa ou dramática) e da lírica para a construção de identidades coletivas, das bases da nacionalidade e mesmo da formação do indivíduo burguês.

A ruptura da forma dramática pode levar a uma narrativização do teatro mais ou menos problematizadora da noção de verdade, da realidade como algo estável e disponível à apreensão cognoscitiva e à reconstituição pelo discurso narrativo. Luiz Alberto recorre de maneira nostálgica à complexa noção de intercâmbio de experiências extraída do conhecido ensaio de Walter Benjamin sobre o narrador ${ }^{29}$. O que Benjamin demonstrou foi a inviabilidade do que chama de transmissibilidade de experiências no contexto histórico em que se desenvolve o romance moderno. A ruptura é constatada como definitiva dentro de um novo quadro sócio-histórico e cultural. $\mathrm{O}$ crítico alemão afirma que é a inviabilidade daquele intercâmbio de experiências que afasta radicalmente o romance como o conhecemos modernamente (gênero ligado fundamentalmente ao campo da vivência individual) do quadro das narrativas tradicionais, cuja função era precisamente promover as trocas capazes de solidificar ou de reforçar os elos e valores coletivos.

Luiz Alberto Abreu fala em "conteúdos narrativos”, para aludir tanto a aspectos referenciais, quanto a traços formais ou de gênero. Mas o que realiza, no texto da Revista $\mathrm{O}$ percevejo, é, em suma, a defesa de um teatro de conteúdos temáticos definidos e de significados comunicáveis, de um reforço do funcionamento cognoscitivo ou formativo e do caráter referencial tradicional da arte teatral. A reflexão que o dramaturgo realiza no texto que publicou na Revista Sala Preta a propósito do personagem, ainda que tenha relação com as questões que ele levanta sobre a narrativa no texto de $\mathrm{O}$ Percevejo, parece mais concentrada e específica, enquanto no texto de $\mathrm{O}$ Percevejo a discussão assume um teor meta-histórico (ontológico e axiológico) sobre a narrativa. De fato, o texto sobre o personagem tem caráter mais técnico-dramatúrgico (de análise de problemas sobre procedimentos composicionais) e se mostra mais delimitado, enquanto levantamento de questões sobre caminhos possíveis de construção do personagem pelos autores no contexto da contemporaneidade. Desse modo, o texto se apresenta como a exposição das inquietações de um dramaturgo inserido em seu tempo e não ganha ares de uma teorização supra-histórica e nostálgica no grau em que isso ocorre no texto de $\mathrm{O}$ percevejo.

$* * *$

Em outro diapasão, Mariângela Alves de Lima, em pequeno artigo incluído em publicação do início dos anos $80^{30}$, postula outros horizontes de análise. Ela tenta, nesse trabalho, entender o desapontamento que os críticos e os produtores teatrais pareciam sentir no momento da atenuação dos mecanismos repressivos e da censura no final da década de 70 . Esse desapontamento, ampla-

29 BENJAMIN, Walter. O narrador. Considerações sobre a obra de Nicolas Leskov. In: Magia e técnica, arte e política. Tradução de Sérgio Paulo Rouanet. São Paulo: Brasiliense, $\overline{1987 . ~ p}$. 197-221. (Obras escolhidas, v. 1).

30 LIMA, Mariângela Alves de. O caos é muito grande. Revista Ensaio Teatro, Rio de Janeiro, p. 7-12, 1983 
mente referido (Yan Michaski, Sábato Magaldi, Guzik e outros), relacionava-se à frustração da expectativa de que, com o fim da vigência do Ato Institucional - AI-5 e com uma retomada (ainda que muito parcial) de certa liberdade de expressão na fase final da ditadura militar, viessem à luz numerosos textos dramáticos construídos a partir de perspectivas formais e políticas variadas, mas tendo sempre uma capacidade de debater as questões político-sociais ou de corresponder aos amplos anseios de discussão acumulados nos anos anteriores e reprimidos pelo poder ditatorial no Brasil.

Ao tratar da situação de certos dramaturgos nos anos 70 e início dos 80, Yan Michaski cunhou a expressão premiados inéditos para se referir a autores que eram reiteradamente premiados em concursos de dramaturgia do extinto Serviço Nacional de Teatro e que não eram encenados (como Wilson Sayão), seja porque a montagem de seus textos era impedida pela censura, seja porque eles não eram absorvidos pelo mercado teatral. Os diretores mais experientes priorizavam outras temáticas, distintas das abordadas nas obras desses autores premiados ou preferiam peças de mais fácil sucesso junto ao público. Já as equipes mais jovens estavam envolvidas em processos como os da criação coletiva e se mostravam ansiosas por falarem de seu cotidiano e das questões que surgiam no seio da sua convivência artística ${ }^{31}$.

A expectativa de que o teatro revelasse, com o fim da ditadura, a força de uma dramaturgia até então reprimida era alimentada, por um lado, pelo conhecimento da enorme quantidade de peças que eram escritas e que reiteradamente eram impedidas de serem encenadas durante o período mais duro da ditadura militar. Por outro lado, o aparecimento de autores de grande vigor no começo do período repressivo - como Leilah Assumpção, Isabel Câmara, Consuelo de Castro, José Vicente, Antônio Bivar e outros - levava a crer que a capacidade de produção no campo da dramaturgia tinha tudo, uma vez desmantelados os mecanismos da repressão e da censura, para gerar um verdadeiro boom, que, entretanto, não se verificou na prática, quando o rigor do aparato autoritário da ditadura começou a se atenuar.

A análise que Mariângela Alves de Lima empreende começa por colocar em questão o conceito de obra no teatro.

Autores e teóricos pensam o texto dramático como alguma coisa a que a encenação dá vida, reinterpreta e amplia. Entretanto, como obra do autor, ele já está completo. A encenação seria o afluente dessa sobredeterminação ${ }^{32}$.

Referindo-se ao período da ditadura e ao momento em que se enseja a abertura gradual da vida política, momento no interior do qual escreve seu artigo da Revista Ensaio Teatro, Mariângela afirma ainda que:

Durante todos esses anos foi impossível para o dramaturgo expressar com clareza as opiniões e as deliberações de consciência sobre o que percebia. Agora é igualmente

${ }_{31}$ MICHALSKI, Yan. Uma categoria paradoxal: os premiados inéditos. Revista Ensaio Teatro, Rio de Janeiro, p. 21-30, 1983.

${ }^{32}$ LIMA, 1983, p. 8. 
difícil compreender-se dentro de um processo cultural que deliberadamente rejeita a autoridade da consciência. Aparentemente o cotidiano se encarrega de provar a desimportância do discurso para organizar qualquer forma de resistência ${ }^{33}$.

Mariângela aqui está fazendo uma menção direta à sensação contemporânea de impossibilidade (por meio de narrativas ordenadas e causais) de sintetizar-se ou de explicar-se (mesmo metaforicamente) a complexidade do mundo social e histórico em que se vive ${ }^{34}$. A sustentação de discursos de ordenamento e de explicação pressupõe, de fato, a existência de horizontes compartilhados como, por exemplo, os de identidade de classe ou de aversão ao autoritarismo político. Como Mariângela explica, os elos que eram favorecidos durante a ditadura tornavam viável a identificação do espectador com todo tipo de personagem rebelde ou marginal, com todo tipo de discurso metafórico da "loucura", selando uma espécie de pacto que envolvia dramaturgos, criadores da cena e receptores.

O que a autora indica é que, no novo contexto dos anos 80 (com o início da diluição da imagem de um inimigo comum), a autoridade da consciência discursivamente organizada, assim como o peso da voz autoral (entendido o autor como sujeito capaz de expressar um sentimento coletivo ou comunitário) perdem o alcance que tiveram na cultura ou no teatro brasileiro nos anos imediatamente anteriores. Agora, nem o engajamento de personagens de peças políticas do início dos anos 60 e nem os desbundados, loucos ou marginais que figuram em textos afinados à contracultura ou à tropicália nos anos 70 dão conta de mobilizar o interesse da platéia. Interesse esse que o teatro, entretanto, angariou amplamente em momentos anteriores (em que a imprensa estava calada, a universidade reprimida e todos os meios de comunicação extremamente controlados).

Podemos, assim, dizer que, nesse contexto, foi bastante viável a continuidade não problemática de certa concepção moderna do espetáculo teatral canonizada no ocidente $^{35}$. Concepção essa que compreende o espetáculo como uma produção que reúne artistas distintos, que se dispõem a fazer ressoar o discurso de uma obra determinada escrita por um autor e coletivamente assimilada pelo elenco e pelos criadores da cena (cenógrafos, iluminadores etc.), sob a liderança ou a regência do encenador. Com efeito, o centramento e a unificação do sentido teatral, como projeto intencional ou deliberado, datam do início do teatro moderno e da afirmação da encenação como linguagem artística, no final do século XIX e nas primeiras décadas do século XX. Podemos, com Mariângela Alves de Lima, afirmar que o mesmo projeto de centramento e de unificação do sentido foram a base da resistência no teatro brasileiro dos anos 60 e 70, tanto da resistência inspirada por um pensamento materialista de esquerda (mais diretamente reprimida), quanto daquela de caráter contracultural (conectada com o que

33 LIMA, 1983, p. 9.

34 Mariângela não se refere a Jean-François Lyotard, mas sua reflexão tem evidentes pontos de conexão com o livro já clássico que Lyotard publica na França em 1979, praticamente no mesmo momento em que a pesquisadora estava escrevendo seu ensaio, produzido em 1980. Lyotard, como é sabido, discorre sobre o contexto cultural do pós-modernismo como sendo o do naufrágio do que chama de as grandes meta-narrativas da modernidade e de sua autoridade para fornecerem explicações e ordenamentos conceituais definitivos sobre o real. LYOTARD, Jean-François. O pós-moderno. Rio de Janeiro: J. Olimpio, 1986. 123 p.

${ }_{35}$ Em uma orientação realista-naturalista (Stanislavski, Antoine) ou com inspiração simbolista (Jacques Copeau). 
ficou conhecido no Brasil como o tropicalismo e a marginália, que também sofreram os constrangimentos da censura e do governo militar).

Para concluir, gostaria ainda de recorrer brevemente a um texto em que Flora Süssekind analisa o trabalho teatral de Gerald Thomas e o de Bia Lessa ${ }^{36}$, destacando em especial um modo complexo de figuração do tempo e uma ênfase na voz narrativa ou na instância organizadora do discurso cênico-dramatúrgico nos espetáculos dos dois encenadores. Para a autora, um dos elementos mais significativos na construção das peças de Bia Lessa e de Gerald Thomas diz respeito à convivência ou à interação entre tempos distintos na estrutura de cada espetáculo. Exemplo dessa imagem de um tempo múltiplo ou bipartido é dado pelas duas Elas, personagens de The flash and crash days, de Thomas. As duas Elas foram interpretadas por atrizes bastante conhecidas, que são mãe e filha - Fernanda Montenegro e Fernanda Torres - e que representavam ficcionalmente as relações de poder e os conflitos geracionais de uma mãe e uma filha.

No que diz respeito à voz narrativa - ou àquilo a que no título do ensaio a autora designa como a "imaginação monológica" -, o texto se refere aos vários modos de auto-representação ficcionalizada dos dois encenadores no interior de seus espetáculos. Um desses modos de auto-representação dos organizadores do discurso são as vozes off, que podem ser ou não as dos próprios encenadores (no caso de Thomas a utilização de sua voz em off é, como se sabe, freqüente) referencialmente associadas aos criadores das peças. As personagens também podem ser meras representações mais ou menos episódicas e irônicas do sujeito enunciador do discurso teatral. É nessa condição que as duas Elas de The flash and crash days são vistas pela ensaísta.

Esses modos de auto-representação da voz ou da instância organizadora do discurso são submetidos, entretanto, a procedimentos diversos de divisão (como é o caso das duas Elas), de auto-ironia e de desautorização. Assim, a ênfase em um sujeito do discurso que preside, de algum modo, ao que se vê e ao que se ouve no espaço da cena, colabora, conforme o raciocínio da ensaísta, para atenuação paradoxal da unidade e da centralidade desse sujeito. Retira-se da voz qualquer função de autolegitimação e de autorização dos conteúdos discursivos possivelmente veiculados. De fato, podemos dizer a respeito dos espetáculos dos dois criadores que tudo o que aparece neles e tudo que é dito ali pode ser igualmente verdadeiro ou falso, pois se associa a um sujeito que pode dizer indiferentemente a verdade ou a mentira, estar brincando ou falando sério, sem oferecer nunca quaisquer garantias de legitimidade confiáveis.

O núcleo reflexivo da leitura realizada por Flora Süssekind constitui-se pelo tema da impossibilidade contemporânea de reconstituição narrativa segura do mundo como objeto, tema que se associa ao da fragmentação do sujeito individual e de sua auto-

\footnotetext{
${ }^{36}$ SÜSSEKIND, Flora. A voz e a série. Rio de Janeiro: Sette Letras; Belo Horizonte: UFMG, 1998. 297 p. Publicado originalmente no mesmo número da Revista da USP em que apareceram os ensaios de Tânia Brandão, Alberto Guzik Sábato Magaldi e Sílvia Fernandes, anteriormente mencionados (SÜSSEKIND, Flora. A imaginação monológica. Revista da USP, São Paulo, n. 14, p. 43-49, jun./ago. 1992), o ensaio de Flora passou a ser referência importante nos estudos voltados para o teatro contemporâneo, como, por exemplo, os de Renato Cohen e de Luiz Fernando Ramos, além da própria Sílvia Fernandes. O texto aparece também em Um encenador de si mesmo: Gerald Thomas (FERNANDES; GUINSBURG, 1996).
} 
-imagem como fonte de um saber racionalmente sustentado e sustentável. Creio que por trás de várias das análises do teatro contemporâneo mais ou menos centradas em dicotomias hierarquizadoras como "teatro de texto" versus "teatro visual" ou "teatro do ator" versus "teatro da imagem" revelam-se as dificuldades de se confrontar (sem pura negação ou ânsia de retorno a uma estabilidade perdida) com o problema crucial que é o das derivas ou do nomadismo do sentido no teatro e na arte contemporânea. É para a necessidade dessa reflexão que apontam certos posicionamentos como os de Flora Süssekind e de outros dos críticos aqui comentados, a exemplo de Mariângela Alves de Lima, no seu texto do início dos anos 80. 


\section{REFERÊNCIAS}

ABREU, Luís Alberto. A personagem contemporânea: uma hipótese. Sala Preta: Revista de Artes Cênicas, São Paulo, ano 1, n. 1, p. 61-68, 2001.

ABREU, Luiz Alberto. A restauração da narrativa. O Percevejo: Revista de Teatro, Crítica e Estética, Rio de Janeiro, ano 8, n. 9, p. 115-125, 2000.

BENJAMIN, Walter. O narrador. Considerações sobre a obra de Nicolas Leskov. In: . Magia e técnica, arte e política. Tradução de Sérgio Paulo Rouanet. São Paulo: Brasiliense, 1987. p. 197-221. (Obras escolhidas, v. 1).

BRANDÃO, Tânia. A estática da palavra. Revista Ensaio Teatro, Rio de Janeiro, p. 13-20, 1983.

BRANDÃO, Tânia. A máquina de repetir e a fábrica de estrelas: Teatro dos Sete. Rio de Janeiro: 7 Letras, 2002.

BRANDÃO, Tânia. Ora direis ouvir estrelas: historiografia e história do teatro brasileiro. Sala Preta: Revista de Artes Cênicas, São Paulo, ano 1, n. 1, p. 169-217, 2001 a.

BRANDÃO, Tânia. Peripécias modernas: Companhia Maria Della Costa (1948-1974). 1998. 2v. Tese (Doutorado) - Instituto de Filosofia e Ciência Sociais, Universidade Federal do Rio de Janeiro, Rio de Janeiro, 1998. Não publicada.

BRANDÃO, Tânia. O teatro brasileiro do século 20. Revista do IPHAN, Brasília, DF, n. 29 , p. 300-335, 2001b.

BRANDÃO, Tânia. Visionários ou alienados. Revista da USP, São Paulo, n. 14, p. 28-33, jun./ago. 1992.

FERNANDES, Sílvia. O espectador emancipado. Revista da USP, São Paulo, n. 14, p. 7073, jun./ago. 1992.

FERNANDES, Sílvia. Grupos teatrais: anos 70. São Paulo: UNICAMP, 2000a.

FERNANDES, Sílvia. Memória e invenção: Gerald Thomas em cena. São Paulo: Perspectiva, 1996.

FERNANDES, Sílvia. Notas sobre dramaturgia contemporânea. O Percevejo: Revista de Teatro, Crítica e Estética, Rio de Janeiro, ano 8, n. 9, p. 25-38, 2000 b.

FERNANDES, Sílvia; GUINSBURG, Jacó (Org.). Um encenador de si mesmo: Gerald Thomas. São Paulo: Perspectiva, 1996. 
GUINSBURG, Jacó. Diálogos sobre teatro. Organização de Armando Sérgio da Silva. São Paulo: Edusp, 1992a.

GUINSBURG, Jacó. O lugar do teatro no contexto da comunicação de massa. Revista da USP, São Paulo, n. 14, p. 92-96, jun./ago. 1992b.

GUINSBURG, Jacó. Texto ou pretexto. Sala Preta: Revista de Artes Cênicas, São Paulo, ano 1, n. 1, p. 87-88, 2001.

GUZIK, Alberto. Um exercício de memória: dramaturgia brasileira anos 80. Revista da USP, São Paulo, n. 14, p. 10-15, jun./ago. 1992.

HELIODORA, Bárbara. Cuidados e carinhos com Clarice. O Globo, Rio de Janeiro, 4 dez. 2002. Segundo Caderno, p. 4.

LIMA, Mariângela Alves de. O caos é muito grande. Revista Ensaio Teatro, Rio de Janeiro, p. 7-12, 1983.

LIMA, Mariângela Alves de. Tendências atuais do teatro. Revista da USP, São Paulo, n. 14, p. 16-21, jun./ago. 1992.

LYOTARD, Jean-François. O pós-moderno. Rio de Janeiro: J. Olimpio, 1986.

MAGALDI, Onde está o teatro. Revista da USP, São Paulo, n. 14, p. 6-9, jun./ago. 1992.

MICHALSKI, Yan. Uma categoria paradoxal: os premiados inéditos. Revista Ensaio Teatro. Rio de Janeiro, p. 21-30, 1983.

NESTROVSKI, Arthur (Org.). Trilogia bíblica: teatro da vertigem. São Paulo: Publifolha, 2002.

PAVIS, Patrice. Le théâtre au croisement des cultures. Paris: Librairie José Corti, 1990. p. 229

PAVIS, Patrice. Vers une théorie de la pratique théâtrale: voix et images de la scène. Septentrion: Presses universitaires de Septentrion, 2000.

SÁ, Nelson de. Divers/Idade: um guia para o teatro dos anos 90. São Paulo: Hucitec, 1997.

SÜSSEKIND, Flora. A imaginação monológica. Revista da USP, São Paulo, n. 14, p. 43-49, jun./ago. 1992

SÜSSEKIND, Flora. A voz e a série. Rio de Janeiro: Sette Letras; Belo Horizonte: UFMG, 1998. 